\title{
Effects of a Blood Transfusion Course Using a Blended Learning Approach on the Acquisition of Clinical Reasoning Skills among Nursing Students in Morocco
}

\author{
https://doi.org/10.3991/ijet.v15i18.15169 \\ Rachid Gouifrane ${ }^{(凶)}$, Halima Lajane, Said Belaaouad, \\ Said Benmokhtar, Said Lotfi \\ Hassan II University of Casablanca, Casablanca, Morocco \\ rachid.gouifranedgmail.com \\ Fatima Dehbi \\ Mohammed VI University of Health Sciences, Casablanca, Morocco. \\ Mohamed Radid \\ Hassan II University of Casablanca, Casablanca, Morocco
}

\begin{abstract}
Learning clinical reasoning skills in nursing education is a challenge for teachers and students. This study investigated the effects of a blended learning program on the acquisition of clinical reasoning skills via a blood transfusion course. The study employed a two group randomised controlled design with an experimental group (group 1, 16 students) and a control group (group 2, 16 students) recruited from a population of second-year nursing students at the Mohamed VI University of Health Sciences in Casablanca, Morocco, during the 2018-2019 academic year. The experimental group received blended instruction, while the control group received traditional classroom instruction over four sessions. One month after the experiment, a post-test was conducted with both groups using 'key-feature questions' that included four clinical situations and 30 questions. The mean scores of the two groups were compared to assess the degree of acquisition of clinical reasoning skills. The mean post-test score was significantly higher in the experimental group than the control group (the p-value of the Mann-Whitney Test is less than 0.05). Moreover, a statistically significant correlation was detected between students' clinical reasoning scores and their theoretical examination marks. These results suggest that blended learning is useful for enhancing the clinical reasoning skills of nursing students, at least in the short term. Thus, it seems appropriate to develop more blended courses and integrate this approach into nursing education programs.
\end{abstract}

Keywords - Blended learning, clinical reasoning, nursing students, blood transfusion. 


\section{Introduction}

Clinical reasoning (CR) is fundamental in nursing practice. It is considered one of the three components of professional competence, distinct from declarative knowledge and procedural skills. It is a complex cognitive process by which nurses analyse and understand the meaning of the data collected from the patient to identify probable clinical judgments and establish a comprehensive care plan [1]. Developing CR skills requires prior mastery of theoretical knowledge and the essential ability to mobilize it in specific clinical situations. This represents a major source of difficulty for students [2]. Traditionally, case studies are the most effective teaching method for increasing the development of critical thinking and problem-solving skills [3]. However, the complexity of health problems and the limited time available for the various courses do not favour the use of these methods. Given these constraints, blended learning (BL) has great potential in nursing education.

The BL is a learning approach that combine face-to-face instruction with e-learning methods, which emphasizes the combination of the best of traditional teaching and the advantages of on-line learning [4]. In particular, it helps students to understand the relevant topics in advance to be better able to learn problem-solving skills in the classroom [5]. It provides the opportunity to deploy specific skills such as understanding, analysis, critical thinking and decision-making [6]. Furthermore, beyond the simple online dissemination of content, the teaching strategies offered by virtual learning environments can foster the development of CR through the use of technical and social interaction tools [7].

The BL approach is increasingly applied in nursing education. Several studies have shown that BL may improve critical thinking and CR skills among nursing students [8-11]. However, no known studies have examined the effects of BL on the acquisition of CR skills related to blood transfusion. Yet, the lack of clinical skills of nurses has been reported as one of the primary causes of transfusion errors [12]. The present study aims to assess the effects of a BL blood transfusion course on the acquisition of CR skills among nursing students.

\section{Methodology}

\subsection{Study design}

A randomized, controlled trial with a two groups post-test design was employed. Traditional classroom instruction and BL were tested with a control group and an experimental group, respectively.

\subsection{Subjects and setting}

The subjects $(\mathrm{N}=32)$ were all second-year nursing students in the Faculty of Health Sciences and Techniques at Mohammed VI University of Health Sciences in Casa- 
blanca, Morocco, during the 2018-2019 academic year. All students were experienced in using the "CANVAS" e-learning management system.

\subsection{Procedure}

The theoretical knowledge about blood transfusion was assessed in both study groups before participation in the learning program. The students were then stratified based on their scores and gender and randomized to the following two groups: control group (A1, n=16) and experimental group (A2, $n=16)$. The two groups received faceto-face instruction in the classroom for 4 weeks from 26 February 2019 to 4 April 2019. The same teacher taught the course to both groups. During this program, subjects in the experimental group were able to use the online learning resources placed on "CANVAS" at any time and place. Four weeks after completing the course, the subjects took a post-test to evaluate the level of acquired CR skills related to blood transfusions.

\subsection{Course design}

The course design was based on the ADDIE model (Analysis, Design, Development, Implementation and Evaluation). The content was structured into four chapters:

1) Blood group systems and labile blood components

2) Clinical transfusion practice

3) Pre-transfusion testing

4) Monitoring transfusion reactions

The content was identical for both groups. However, the organization of the content differed depending on the teaching method.

The control group received traditional classroom instruction using interactive presentations, demonstration videos, case studies and practical exercises. In contrast, the experimental group was required to use online materials related to each chapter before entering the face-to-face sessions. Online resources were available two weeks before the course and included web lectures, care procedures, interactives videos and quizzes using multiple-choice questions (MCQs). The chronology of consultation was programmed by the teacher following a logical order that began with the lectures and ended with the self-assessment quizzes. Interactive videos and context rich MCQs were used to promote the development of CR skills. A discussion forum was created to enhance interactions between small-sized groups. Classroom sessions provided an opportunity to promote the integration of knowledge through practical works and clinical case studies. The content validity of the developed course was determined by three professors of nursing. 


\subsection{Measurement tool}

Based on the CR strategies identified by Fonteyn [13] and the educational objectives of the course, six nursing educators built and validated a CR test for blood transfusion situations composed of 30 questions. It included 'key-feature questions' [14] regarding four clinical situations. Each situation began with a clinical vignette followed by multiple-choice questions and/or open-ended questions. This instrument aimed to test the students' ability to analyse a care situation based on a clinical case in which a blood transfusion was required. Students were asked, among other things, to decide on the relevance of blood transfusion based on the pre-transfusion testing results, and to identify the main transfusion incidents while making the appropriate decisions. Specifically, the test aimed to assess the students' ability to

1) Identify relevant clues by linking information

2) Search for missing information

3) Generate hypotheses and clinical judgements

4) Make effective clinical decisions

5) Provide explanations.

\subsection{Data analysis}

We analysed data from only 15 experimental group students and 15 control group students, as two students did not complete the training and testing procedure. To ensure greater reliability, the test was processed by two different evaluators using a standard answer key approved by experts. Demographic characteristics were analysed by descriptive statistics. The limited sample size dictated the use of a non-parametric statistical test. We used the Mann-Whitney $U$ test to compare mean scores between the groups, and Fisher's exact test and chi-square tests were used to test homogeneity. Pearson's correlation coefficient was used to test correlations between variables. A probability value of $p<0.05$ was considered statistically significant. The data was analysed using the IBM SPSS ver. 20 for Windows (SPSS Inc., Chicago, IL, USA).

\subsection{Ethical considerations}

This study was initiated after approval from the educational department of the Faculty of Health Sciences and Techniques at Mohammed VI University of Health Sciences in Casablanca, Morocco. Participation in the study was voluntary. The written informed consent of the students participating was obtained after explanation of the topic and purpose of the study. Students were reassured that their identities would remain confidential and that academic progress would not be affected by participation or the decision to withdraw at any time. 


\section{Results}

\subsection{General characteristics and homogeneity of participants}

The mean age of the students was $18.70 \pm 1.53$. Most of the students were female (76.7\%) and achieved the baccalaureate A level (86.7\%). Their mean score for the last term was $13.16 \pm 2.03$. The majority of the students had no experience of blood transfusion in a practicum setting. The Fisher's exact test, Pearson Chi-square and MannWhitney $U$ test showed that the groups did not differ significantly from each other in terms of age, level of study, first term marks, blood transfusion knowledge or experience of blood transfusion during clinical practicum $(\mathrm{P}>0.05)$. Thus, the homogeneity between the groups was confirmed (see figure 1).

\begin{tabular}{|c|c|c|c|c|c|c|}
\hline \multirow[t]{2}{*}{ Characteristics } & & \multicolumn{2}{|c|}{ Experimental group } & \multicolumn{2}{|c|}{ Control group } & \multirow[t]{2}{*}{ P-Value } \\
\hline & & $\mathbf{N}$ & $\%$ & $\mathbf{N}$ & $\%$ & \\
\hline \multirow[t]{2}{*}{ Gender } & $\mathbf{F}$ & 12 & $44 \%$ & 11 & $36.6 \%$ & $1.00^{\text {a) }}$ \\
\hline & M & 3 & $10 \%$ & 4 & $13.3 \%$ & \\
\hline \multirow[t]{3}{*}{ Education level } & $\mathrm{Bac} d)$ & 13 & $86.7 \%$ & 13 & $86.7 \%$ & $0.51^{b)}$ \\
\hline & $\mathrm{Bac}^{d(d)}+1$ & 01 & $6.7 \%$ & 02 & $13.7 \%$ & \\
\hline & $\mathrm{Bac}^{d)}+2$ & 01 & $6.7 \%$ & 00 & 00 & \\
\hline \multirow{3}{*}{$\begin{array}{l}\text { Experience of blood } \\
\text { transfusion during } \\
\text { clinical practicum }\end{array}$} & Yes & 02 & $13.3 \%$ & 03 & $20 \%$ & $1.00 \mathrm{a})$ \\
\hline & No & 13 & $86.7 \%$ & 12 & $80 \%$ & \\
\hline & & Mean & SD & Mean & SD & \\
\hline \multicolumn{2}{|l|}{ First term marks } & 13.06 & 2.01 & 13.26 & 2.12 & $\left.0.753^{c}\right)$ \\
\hline \multicolumn{2}{|c|}{ Age } & 18.66 & 1.39 & 18.73 & 1.70 & 0.649 b) \\
\hline \multicolumn{2}{|c|}{ Theoretical Knowledge scores } & 6.65 & 2.00 & 6.78 & 1.26 & 0.819 c) \\
\hline
\end{tabular}

Fig. 1. Comparisons of general characteristics between the experimental and control groups

\subsection{Differences in clinical reasoning skills after participation in the blood transfusion course}

As shown in Figure 2, the mean score for CR skills after education was significantly higher in the experimental group $(11.60 \pm 2.24)$ than in the control group (7.63 \pm 4.57$)$. The Mann-Whitney U-test shows a statistically significant difference between the CR skills means of the two groups after the intervention $(p<0.05)$. 


\begin{tabular}{lcccc}
\hline \multirow{2}{*}{ Groups } & \multicolumn{2}{c}{ After the intervention } & \multicolumn{2}{c}{ Mann-Whitney U-test } \\
\cline { 2 - 5 } & Mean & SD & $\mathrm{Z}$ & $\mathrm{P}$ \\
\hline \multirow{2}{*}{ Experimental group } & 11.60 & 2.24 & 51.00 & 0.011 \\
Control group & 7.63 & 4.57 & & \\
\hline
\end{tabular}

Fig. 2. Differences in clinical reasoning skills after the learning program

\subsection{Correlation between clinical reasoning and theoretical knowledge post-} test scores

Pearson's correlation coefficient shows a statistically significant correlation between students' CR post-test scores and their theoretical examination marks ( $\mathrm{r}=$ $0.673, \mathrm{p}=0.000$ ) (see Figure 3).

\begin{tabular}{lcc}
\hline & & $\begin{array}{c}\text { Clinical reasoning post-test } \\
\text { scores }\end{array}$ \\
\hline Theoretical examination marks & Pearson r correlation & $\left.0.673^{\mathrm{a}}\right)$ \\
& $\mathrm{P}$ & 0.000 \\
& Number & 30 \\
\hline
\end{tabular}

Fig. 3. Correlation between clinical reasoning and theoretical knowledge post-test scores

\section{Discussion}

This study examined the effects of a BL approach on the acquisition of CR skills related to blood transfusion by comparing two groups of nursing students. The level of theoretical knowledge of the two groups was similar at the beginning of the course. After the educational intervention, the results show that the introduction of BL improved students' CR skills more than traditional classroom teaching. The experimental group performed $52.03 \%$ better than the control group. These results are consistent with those of Dehghanzadeh [9], Jang and Hong [10] and Sadhuwong et al. [11], who found significantly higher mean scores for critical thinking and CR skills in the BL groups than the traditional course groups.

Based on the CR test used in this experiment, it can be deduced that the experimental group was more likely to

1) Understand the meaning of the data by linking the information together

2) Search for missing information

3) Generate hypotheses and clinical judgments

4) Make clinical decisions

5) Provide explanations 
Thus, it can be said that BL can help students overcome some of the CR difficulties identified in the literature, including difficulty in selecting relevant clues [15], linking information [16] and making clinical hypotheses or judgements [17].

The results of the present study also show a statistically significant correlation between students' CR post-test scores and their theoretical examination marks. This confirms previous studies that the acquisition of theoretical knowledge is a prerequisite for the development of CR skills [2]. It seems, therefore, that BL could promote a quick transition from simple memorization of knowledge to more advanced levels of analysis by using effective e-learning devices and by increasing the time reserved for face-to-face case studies.

Indeed, a deeper investment was expected from students at home to benefit from face-to-face time and promote knowledge integration. It was also expected that online methods such as case based MCQs, interactive videos and online discussion would increase critical thinking and clinical problem-solving skills. Several studies have reported similar findings, including the experimental study by Chen and Chuang [18], who found that online quizzes significantly improved student learning, at least in the short term. In the literature review by Coyn et al. [8], a BL model incorporating online video resources was shown to be a useful tool for teaching clinical skills to nursing students. In addition, the study conducted by Afify [19] revealed that asynchronous online discussion improved students' critical thinking skills when used with smallsized groups.

\section{$5 \quad$ Limitations}

This research is one of the first studies to evaluate the impact of BL approach on the acquisition of CR skills related to blood transfusion. Consequently, it was difficult to compare the results with those of other studies, hence the need to initiate studies using a similar design. This study has some limitations. First, the study outcomes were measured four weeks after the blood transfusion course and but not measured later. Therefore, we are not sure of the long-term effects of the intervention provided. Thus, it would be desirable to adopt time-series measures in future studies. Second, the study was conducted in a single university in Morocco, and the number of students enrolled during the academic year of the experiment was limited. Therefore, the results obtained may not be generalized. Thirdly, the test used assesses all the steps of the clinical reasoning process. However, its use is more feasible in an academic setting. Thus, we recommend the use of additional tools in clinical settings.

\section{Conclusion}

The results of the study showed that BL was an effective method in improving students' CR skills compared to traditional classroom teaching. It may serve as a promising approach, especially when combined with high-fidelity clinical simulation, to better prepare students to adapt to different clinical situations. The development and implementation of the blended blood transfusion course in this study may contribute 
to reducing the risk of transfusion incidents and errors, and the development of more blended courses and integration of this approach in nursing education programs would be beneficial.

\section{$7 \quad$ References}

[1] Levett-Jones T, Hoffman K, Dempsey J, Jeong SY-S, Noble D, Norton CA, Roche J, Hickey N. The "five rights" of clinical reasoning: An educational model to enhance nursing students' ability to identify and manage clinically "at risk" patients. Nurse Education Today. 2010; 30(6), 515-520. https://doi.org/10.1016/j.nedt.2009.10.020

[2] Fonteyn M, Ritter B. Clinical reasoning in nursing. In: Higgs J, Jones M, Loftus S, Christensen N. Clinical reasoning in the health professions 3rd.ed, Butterworth Heinemann Elsevier, 2008. p. 235-242.

[3] Popil, I. Promotion of critical thinking by using case studies as teaching method. Nurse Education Today. 2011; 31(2), 204-207.https://doi.org/10.1016/j.nedt.2010.06.002

[4] Rasmitadila et al. Using Blended Learning Approach (BLA) in Inclusive Education Course: A Study Investigating Teacher Students' Perception. International Journal of Emerging Technologies in Learning (iJET). 2020. 15(02), 72-85. Available at: 〈https://online-journals.org/index.php/i-jet/article/view/9285/6421>. Date accessed: 10 Apr. 2020. https://doi.org/10.3991/ijet.v15i02.9285.

[5] Saovapa W. A Development of the Blended Learning Model Using Edmodo for Maximizing Students' Oral Proficiency and Motivation. International Journal of Emerging Technologies in Learning (iJET). 2017. 12(02), 137-154. Available at: <https://onlinejournals.org/index.php/i-jet/article/view/6324/4294>. Date accessed 02 Apr. 2020. https:// doi.org/10.3991/ijet.v12i02.6324.

[6] Robley LR, Farnsworth BJ, Flynn JB, Horne CD. This new house: Building knowledge through online learning. Journal of Professional Nursing. 2004; 20(5), 333-343. https://doi. org/10.1016/j.profnurs.2004.07.012

[7] French National Authority for Health. Good Practice Guidelines on Health Apps and Smart Devices (Mobile Health or mHealth). France, 2015. Available from :https://www.hassante.fr/upload/docs/application/pdf/201703/dir1/good_practice_guideline s_on_health_apps_and_smart_devices_mobile_health_or_mhealth.pdf. https://doi.org/10.21037/mhealth.2018.03.02

[8] Coyne E, Rands H, Frommolt V, Kain V, Plugge M, Mitchell M. Investigation of blended learning video resources to teach health students clinical skills: An integrative review. Nurse Education Today. 2018; 63, 101-107. https://doi.org/10.1016/j.nedt.2018.01.021

[9] Dehghanzadeh S, Jafaraghaie F. Comparing the effects of traditional lecture and flipped classroom on nursing students' critical thinking disposition: A quasi-experimental study. Nurse Education Today. 2018; 71: 151-156. https://doi.org/10.1016/j.nedt.2018.09.027

[10] Jang HJ, Hong SY. Effect of Blended Learning in Nursing Education. International Journal of Multimedia and Ubiquitous Engineering. 2016; 11(5), 297-304. https://doi.org/10.142 57/ijmue.2016.11.5.27

[11] Sadhuwong K, Koraneekij P, Natakuatoong O. Effects of a Blended Learning Model Integrating Situated Multimedia Lessons and Cognitive Apprenticeship Method on the Clinical Reasoning Skills of Nursing Students. Journal of Health Research. 2016; 30:6. http://doi. org/10.14456/jhr.2016.56 
[12] Rowe R, Doughty H. Observation and documentation of bedside blood transfusion. British journal of nursing (Mark Allen Publishing). 2000; 9(16), 1054-1058. http://doi.org/10.129 68/bjon.2000.9.16.12449

[13] Fonteyn M. Thinking strategies for nursing practice. Philadelphie, Lippincott; 1998. 315 p.

[14] Nayer M, Glover Takahashi S, Hrynchak P. Twelve tips for developing key-feature questions (KFQ) for effective assessment of clinical reasoning. Medical Teacher. 2018; 40(11) 1116-22. http://doi.org/10.1080/0142159X.2018.1481281

[15] Hoffman K, Dempsey J, Levett-Jones T, Noble D, Hickey N, Jeong S, Hunter S, Norton C. The design and implementation of an Interactive Computerised Decision Support Framework (ICDSF) as a strategy to improve nursing students' clinical reasoning skills. Nurse Education Today. 2011; 31(6), 587-594. https://doi.org/10.1016/j.nedt.2010.10.012

[16] Demeester A, Eymard C, Vanpee D. Learning clinical reasoning: identified difficulties for future midwives. Revue Française de Pédagogie. 2012; (181), 43-54. https://doi.org/10. 4000/rfp.3906

[17] Perrier C. Learning clinical reasoning in nursing using short vignettes: An exploratory study. Recherche En Soins Infirmiers. 2014; 118(3), 52. https://doi.org/10.3917/rsi.118.00 $\underline{52}$

[18] Chen H-Y, Chuang C-H. The learning effectiveness of nursing students using online testing as an assistant tool : A cluster randomized controlled trial. Nurse Education Today. 2012; 32(3), 208-213. https://doi.org/10.1016/j.nedt.2011.03.004

[19] Afify, MK. The Influence of Group Size in the Asynchronous Online Discussions on the Development of Critical Thinking Skills, and on Improving Students' Performance in Online Discussion Forum. International Journal of Emerging Technologies in Learning (iJET). 2019; $14 \quad$ (05), 132-152. Available at: <https://www.onlinejournals.org/index.php/i-jet/article/view/9351/5522>. Date accessed: 01 Apr. 2020. https://doi.org/10.3991/ijet.v14i05.9351.

\section{Authors}

Rachid Gouifrane is a Ph.Dc in Educational Technology. He is a Nurse Teacher and the head of continuing education office at Ibn Rochd hospital of Casablanca, Morocco. He is a member of Laboratory of Physical Chemistry of Materials at Ben M'Sik Faculty of Sciences (LCPM), Hassan II University of Casablanca, Morocco.

Halima Lajane is a Ph.Dc in Educational Technology. She is a Nurse Teacher and the head of continuing education office at Ibn Rochd hospital of Casablanca, Morocco. Section Morocco. She is a member of Laboratory of Physical Chemistry of Materials (LCPM) at Ben M'Sik Faculty of Sciences, Hassan II University of Casablanca, Morocco.

Said Lotfi is a PhD in Education assessment measure. He is a member of Laboratory of Education and Training Sciences. Evaluation of Sport Sciences and Didactic of Physical Activity. He is a Professor at Higher Normal School (ENS), Hassan II University of Casablanca, BP 50069, Ghandi,, Casablanca Morocco.

Said Belaaouad: is a PhD in Physical Chemistry. He is a Professor of Higher Education at Faculty of Sciences Ben M'Sik, University Hassan II of Casablanca, Morocco, B.P 7955 Sidi Othmane. He is the Director of the Laboratory of Physical Chemis- 
try of Materials. He operates in several fields of educational sciences: educational technologies and assessment.

Said Benmokhtar: is a PhD in Physical Chemistry. He is a Professor of Higher Education at Faculty of Sciences Ben M'Sik, University Hassan II of Casablanca, Morocco, B.P 7955 Sidi Othmane. He is an Expert in the fields of teaching and research on educational and technologies assessment, engineering of assessment, Chemistry Didactics, University Pedagogy.

Fatima Dehbi : is a $\mathrm{PhD}$ in medicine. She is a Professor of Higher Education at Faculty of Medicine, University Hassan II of Casablanca, Morocco. She was the dean of the Faculty of Health Sciences and Techniques, Mohammed VI University of Health Sciences, Casablanca, Morocco. She operates in several fields of educational sciences: University Pedagogy educational technologies and assessment, engineering of assessment.

Mohamed Radid is a PhD in Physical Chemistry. He is currently the Vice Dean of the Faculty of Sciences Ben M'Sik at Hassan II University, B.P 7955 Sidi Othmane, Casablanca, Morocco since 2014. He is a Member of the Observatory of Research in Didactics and University Pedagogy (ORDIPU) and Member Board of Directors of Association for the Development of Evaluation Methodologies in Education (ADMEE) - Europe. He is an Expert in the fields of teaching and research on educational and technologies assessment, engineering of assessment, Chemistry Didactics, University Pedagogy.

Article submitted 2020-04-23. Resubmitted 2020-05-25. Final acceptance 2020-05-28. Final version published as submitted by the authors. 